\title{
Analysis of Cytotoxic Effects of Medical Gas-Discharge Devices
}

\author{
DOI: 10.17691/stm2017.9.1.15
}

Received October 12, 2016

K.A. Astafyeva, Junior Researcher, Department of Physicochemical Researches,

Central Scientific Research Laboratory;

I.P. Ivanova, DSc, Head of the Department of Physicochemical Researches,

Central Scientific Research Laboratory

Nizhny Novgorod State Medical Academy, 10/1 Minin and Pozharsky Square, Nizhny Novgorod, 603005,

Russian Federation

The aim of the investigation was to analyze cytotoxic effects of various gas-discharge technologies.

Materials and Methods. The following gas-discharge devices were used in the work: Pilimin series IR-1, IR-10 and Brig - radiation of spark discharge plasma; DBK-9 low-pressure mercury lamp - ultraviolet radiation; Corona device for darsonvalization - silent electric corona discharge. The objects of investigation were erythrocytes of Wistar rats, and lymphoid cells of Pliss lymphosarcoma.

Results. All examined gas-discharge devices were established to possess membranotoxic and cytotoxic effects. The total number of erythrocytes and lymphoid cells diminished, while the number of nonviable cells grew with the increase of exposure time. Erythrocyte membrane was least resistant to the radiation of the spark discharge plasma with 1,500 $\mu$ s pulse duration and to ultraviolet radiation of the mercury lamp, whereas erythrocytes were less resistant to the radiation by the gas-discharge devices than lymphoid cells. Pliss lymphosarcoma cells appeared to be more sensitive to the action of spark discharge plasma and corona discharge with 1-10 $\mu$ s pulse duration. Radiation of spark discharge plasma with $150 \mu$ s pulse duration exhibited equally membranotoxic and cytotoxic effect.

Conclusion. The results of assessing cytotoxic effect of various gas-discharge devices help to determine the direction of investigations when mechanisms of action of gas-discharge technologies are explored, and to recommend, in particular, a more profound study of such parameter as pulse discharge duration.

Key words: gas-discharge technologies; radiation of spark discharge plasma; ultraviolet radiation; Darsonval corona discharge.

The increasing number of neoplastic and infectious processes resistant to traditional methods of treatment (radiotherapy, chemotherapy, antibiotic therapy) stipulate the search and development of novel effective methods of inhibiting proliferative activity of neoplastic and prokaryotic cells, which possess cytotoxic effect and do not cause pronounced toxic effect on the organism as a whole. In this connection, gas-discharge plasma technologies applied both in Russia and abroad are of great interest [1-3]. Such medical gas-discharge devices as quartz lamp (discharge of mercury vapors) [4] and apparatus for darsonvalization (silent corona discharge) [5] are widely being used in Russia. Biological effects of recently developed gas-discharge Brig devices (Sarov, Nizhny Novgorod region, Russia) and Pilimin (Moscow, Russia), based on radiation of plasma spark discharge, are being investigated [6-9].

To assess the efficacy of cytotoxic effect of any physical or chemical factor, it is necessary to carry out a primary screening to evaluate the resistance of the membrane and the cell as a whole to the action being examined. The analysis of structural and functional state of the cell phospholipid bilayer makes it possible to evaluate the deepness of membranotoxic effect. Screening investigations enable the researchers to suggest recommendations for developing new and optimizing the existing medical devices.

The aim of the investigation was to analyze cytotoxic effects of various medical gas-discharge devices.

Materials and Methods. The following gas-discharge devices were used in the work: Corona (Novator, Ukraine) - a silent electric corona discharge, $10 \mu \mathrm{s}$ pulse duration, $100 \pm 10 \mathrm{~Hz}$ pulse repetition frequency, 16 kV output voltage; Pilimin IR-1 (D.V. Skobeltsin Institute of Nuclear Physics of Moscow State University, Moscow, Russia) - pulse radiation of spark discharge plasma (200-800 nm), 1,500 us pulse duration, $1.8 \mathrm{~J}$ pulse energy, $1 \mathrm{~Hz}$ pulse frequency; Pilimin IR-10 - pulse radiation of spark discharge plasma

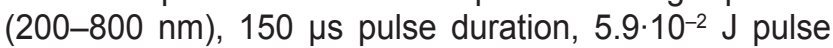
energy, $10 \mathrm{~Hz}$ pulse frequency; Brig (Russian Federal Nuclear Center, Sarov, Nizhny Novgorod region, Russia) - pulse radiation of spark discharge plasma (200-800 nm), 1-4 $\mu$ s pulse duration, $5 \mathrm{~J}$ pulse energy, $1 \mathrm{~Hz}$ pulse frequency; DBK-9 low-pressure mercury

For contacts: Irina P. Ivanova, e-mail: ivanova.ip@mail.ru 
lamp (Solnyshko, Russia) - ultraviolet radiation (220$400 \mathrm{~nm}$ ), discharge is generated in mercury vapors, $9 \mathrm{~W}$ power, an average ultraviolet radiation photon flux

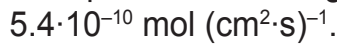

The experiment was carried out using suspensions of Wistar rat erythrocytes, and suspensions of Pliss lymphosarcoma lymphoid cells. The cell strain was received from N.N. Blokhin Russian Cancer Research Center (Moscow, Russia).

The erythrocyte suspension was prepared in the following way: animals were introduced $0.2 \mathrm{ml}$ of heparin intraperitoneally, decapitated under ether anesthesia, the whole blood was collected to the test-tube with $0.2 \mathrm{ml}$ of heparin, and centrifuged at 3,000 rpm. Erythrocytes were diluted 1,000 times with Hanks' solution (Biolot, Russia) with final concentration of (5-8) $10^{7} \mathrm{cells} / \mathrm{ml}$.

The work was performed in accordance with ethical principles established by European Convention for the Protection of Vertebrata used for Experimental and other Scientific Purposes (the Convention was passed in Strasburg, March 18, 1986, adopted in Strasburg, June 15, 2006) and approved by Ethics Committee of Nizhny Novgorod State Medical Academy.

The suspension of lymphoid cells was obtained by disrupting Pliss lymphosarcoma tissue in Hank's solution, and then brought to a final concentration of $(5-7) \cdot 10^{6} \mathrm{cell} / \mathrm{s} / \mathrm{ml}$.

To assess cytotoxic effects, the cells in $4 \mathrm{ml}$ volume and in $40 \mathrm{~mm}$-diameter sterile plastic Petri dishes were exposed to the tested physical factors for $30 ; 60 ; 120$; $300 ; 600 ; 1,200 ; 2,400 ; 3,600 \mathrm{~s}$. Untreated suspensions of erythrocytes and lymphoid cells served as a control.

The total number of cells after the exposure was determined by means of Sceptor automatic cytometer (Merck Millipore, USA). The number of nonviable cells after incubation with trypan blue was evaluated microscopically (Leica BME; Leica Microsystems, Germany) in the chamber for cell count for $5 \mathrm{~min}$ ( $5 \mathrm{mg} / 10 \mathrm{ml}$ of the sterile physiological solution).

Microviscosity in the zone protein-lipid contacts and lipid bilayer of the membranes was determined by the fluorescence of pyrene probe (Sigma-Aldrich, USA), diluting 20 times the solution of pyrene in $0.85 \mathrm{mg} /$ $\mathrm{ml}$ ethanol [10]. The degree of hydrophobicity was determined by the fluorescence of 1,6-diphenyl-1,3,5hexatriene (DPH) probe (Sigma-Aldrich, USA), for the investigation, the DPH solution in $1 \mathrm{mg} / \mathrm{ml}$ of hexane was diluted 100 times [11]. Measurements were conducted using Fluorat-02 Panorama spectrofluorometer (Lumex, Russia).

The data obtained in the experiment were processed using Exel, Statistica 8.0 applied program packages. The results are presented as $M \pm m$, where $M$ is arithmetic mean, $m$ is error of mean. Statistical significance of the mean differences was determined using the parametric Student's test. Differences were considered significant at $p<0.05$.

Results and Discussion. The reduction of the total cell number after the exposure testifies to the presence of cytotoxic effect. One of the most convenient models of the membrane resistance assessment are erythrocytes. Therefore, at the first stage, changes of the total number of these cells after the exposure were evaluated. For all tested devices, the total number of erythrocytes was estimated to decrease with the increase of the exposure time, while the number of nonviable cells to rise (Figure 1 (a)). In the course of the investigation, we defined the time modes at which 50\% cytotoxic effect was observed. For Pilimin IR-1, IR-10 and DBK-9 mercury lamp this time was $30 \mathrm{~s}$, for Brig $60 \mathrm{~s}$, for Corona (Darsonval corona discharge) this time amounted to 300 s. $100 \%$ cytotoxic effect was registered after exposure to DBK-9 and Pilimin IR-10 radiation for $600 \mathrm{~s}$. For Brig and Corona, erythrocyte hemolysis was not noted even after the maximal exposure time ( $3,600 \mathrm{~s}), 9$ and $27 \%$ of cells, respectively, remained in the suspension.

The automatic cytometer can determine the total number of cells but not their viability. Therefore, a vital test with trypan blue was used to detect nonviable cells.

The number of nonviable cells was estimated to grow with the increase of time the erythrocyte suspension is irradiated by the tested devices (Figure 1 (b)).

Complete erythrocyte hemolysis was observed after irradiation by DBK-9 mercury lamp and Pilimin IR-1 spark discharge plasma device for 1,200 s. After maximal exposure to Brig plasma for $3,600 \mathrm{~s}$, no viable erythrocytes left in the suspension, and after exposure to Corona radiation, $46 \%$ of the cells retain their viability, and $56 \%$ were nonviable.

Thus, rat erythrocyte membranes appeared to be more resistant to plasma exposure of Brig and Corona devices, which is likely to be connected with a shorter pulse duration (1-10 $\mu \mathrm{s})$ compared to Pilimin IR-1 and IR-10 with 150 and $1,500 \mu$ s pulse duration. It is known that at a short pulse duration accumulation of radicals and active particles in the substrate runs slower [4] and, therefore, erythrocytes also hemolyze slower in such situation, and a greater quantity of cells retain the viability. A protein cytoskeleton of erythrocytes responsible for elasticity and integrity of the membrane [12] is subjected to destructive changes to the greater extent after exposure to spark discharge plasma with $1,500 \mu \mathrm{s}$ pulse duration and ultraviolet radiation of the mercury lamp.

At the next stage, the effect of the gas-discharge devices on the alteration of the total number and viability of lymphoid cell was analyzed, as these cells possess a more complex organization than erythrocytes, have a nucleus and intracellular organelles. It was established that the total number of lymphoid cells decreased with the increase of exposure time (Figure $2(a)$ ), while the number of nonviable cells grew (Figure 2 (b)). $50 \%$ lysis of the cells was observed after irradiation with Pilimin $\mathrm{IR}-10$ and Corona for $30 \mathrm{~s}$, the mercury lamp and Brig for 120 s, Pilimin IR-1 for 600 s. $100 \%$ cytotoxic 


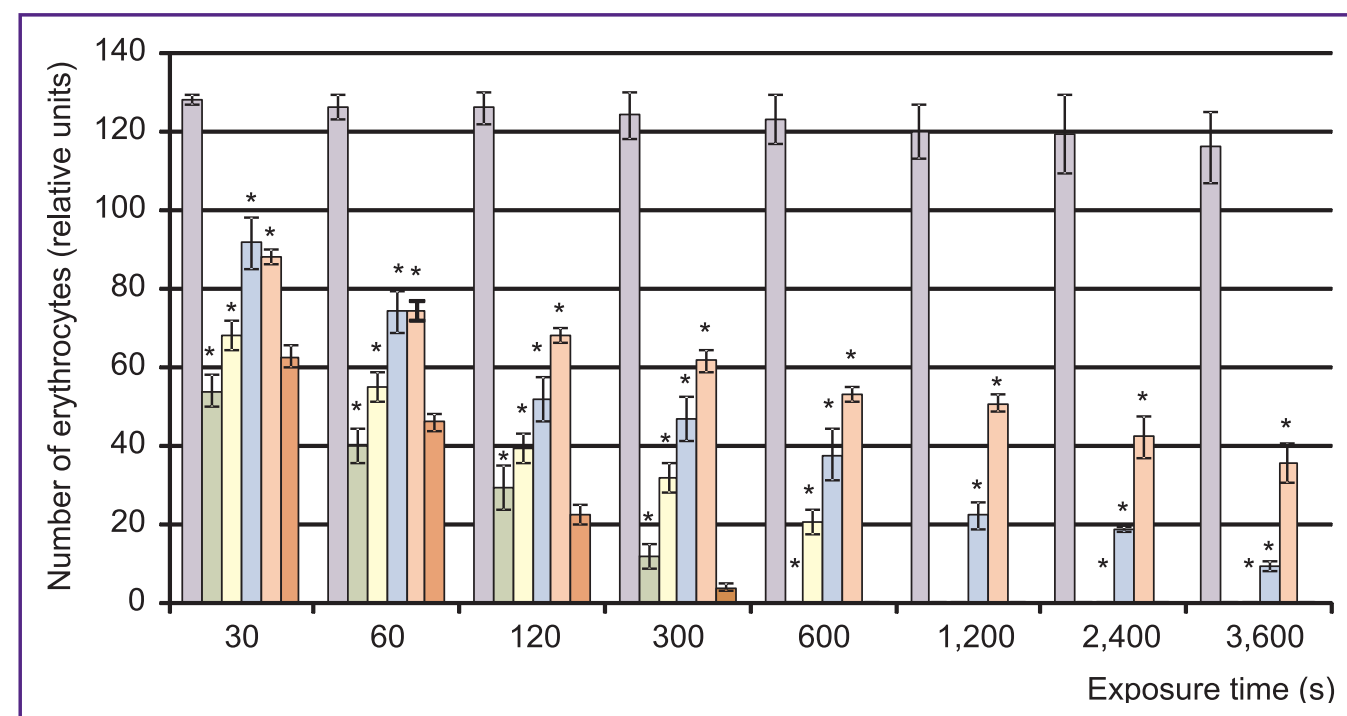

a

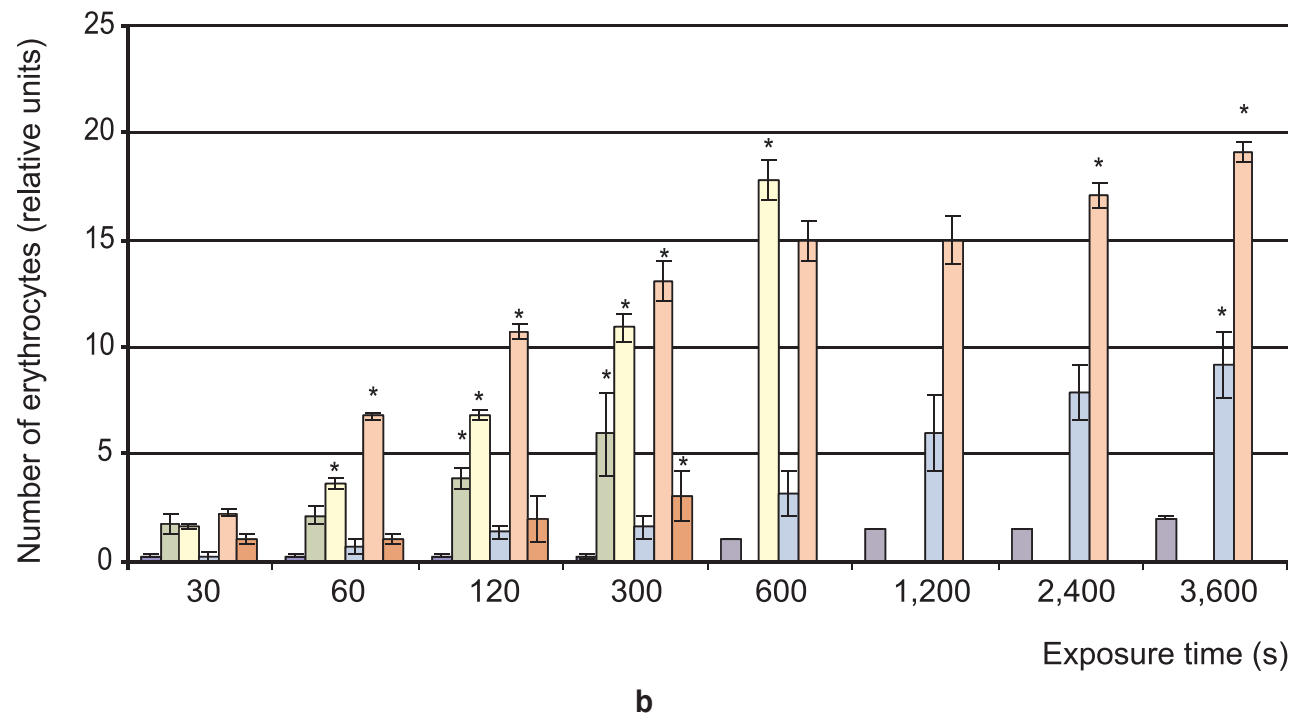

$\square$ Control $\square$ Pilimin IR-1 $\square$ Pilimin IR-10 $\square$ Brig $\square$ Corona $\square$ DBK-9

Figure 1. Alterations of erythrocytes after irradiation by gas-discharge devices: (a) total number of cells; (b) quantity of nonviable cells; * statistical significance of differences with the control group, $p<0.05$

effect during maximal exposure time $(3,600 \mathrm{~s})$ was not established. However, the number of nonviable cell after 3,600 s exposure to Pilimin IR-1 radiation amounted to $75 \%$, DBK- $9-86 \%$, Pilimin IR- $10-66 \%$, Brig - 83\%, Corona $-52 \%$.

Thus, all examined gas-discharge devices possess both membranotoxic and cytotoxic effect. Lymphoid cells are more resistant to the irradiation by spark discharge plasma of Pilimin IR-1, whereas erythrocyte membranes, on the contrary, are more sensitive to it. Pulse duration of spark discharge plasma radiation of the given device 1,000 times greater than that of Brig device and 100 times of Pilimin IR-10. It is the high duration of the pulse that is most likely to be of importance for destruction and lysis of erythrocyte, while for the nuclear cells with numerous membrane formations (nuclear membrane, Golgi complex, endoplasmic reticulum, and so on) the reduction of viability is connected with integral accumulation of destructive changes in the membrane structures under a shorter duration of the pulse radiation. This fact leads to the conclusion that such parameter as duration of the discharge pulse should be taken into consideration when biomedical gas-discharge devices are developed.

Comparing cytotoxic effects of gas-discharge technologies on erythrocytes and lymphoid cells we may conclude that neoplastic lymphoid cells are more resistant to the impact of the tested gas-discharge 


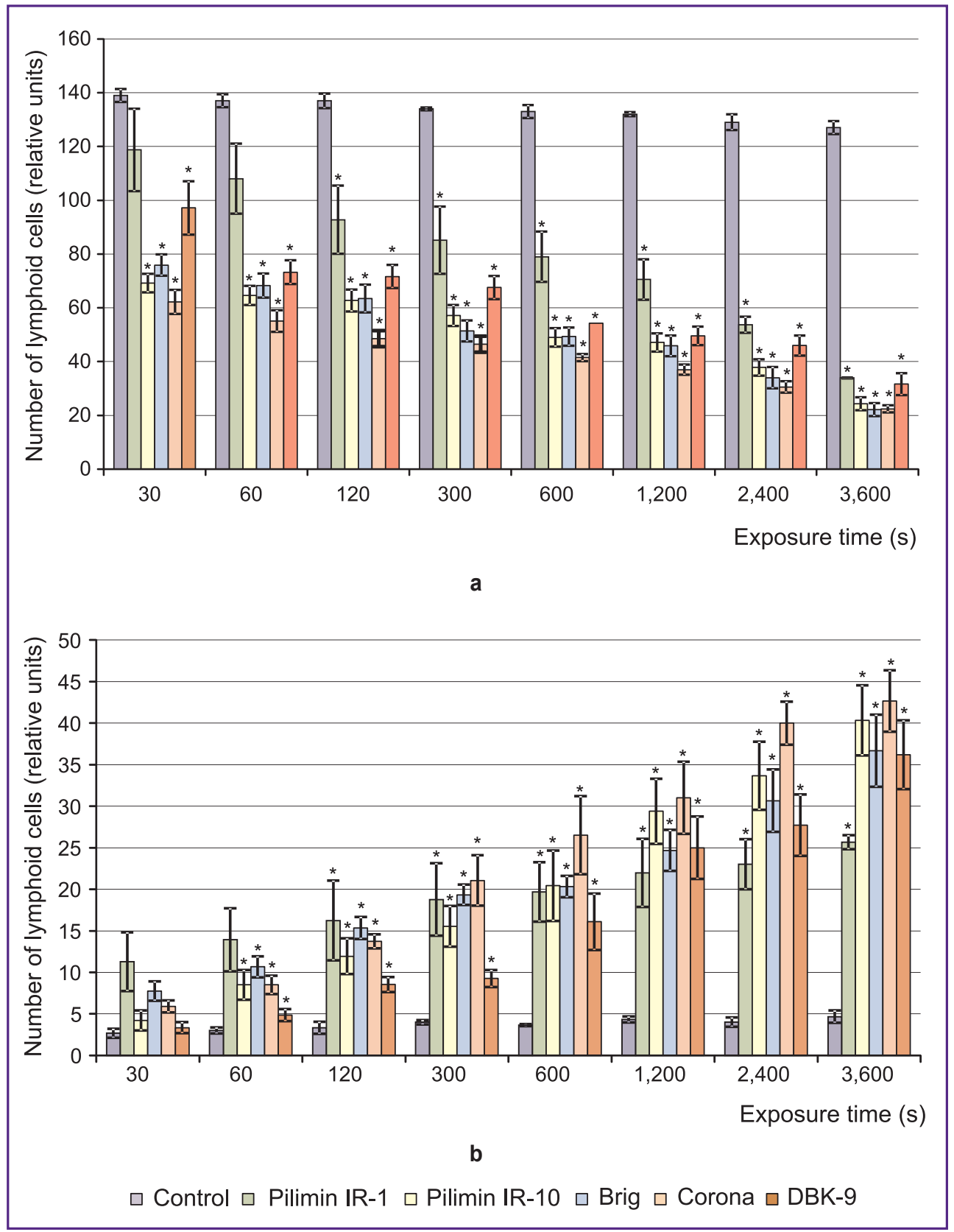

Figure 2. Alterations of lymphoid cells after irradiation by gas-discharge devices: (a) total number of cells; (b) quantity of nonviable cells; * statistical significance of differences with the control group, $\mathrm{p}<0.05$

devices, as their greater quantity, compared to erythrocytes, preserve their integrity and viability with the increase of exposure time, which is likely to be linked with the larger size $(8-18 \mu \mathrm{m}$, which is 3 to 4 times greater the sizes of erythrocytes), availability of a well-formed nucleus, organelles, and with an increased metabolic activity of neoplastic cells [13].

It should be noted that investigation of cell resistance and viability does not allow us to evaluate to the full extent the impairments in the structural and functional membrane organization. Therefore, such additional parameters as hydrophobic properties and microviscosity of the lipid bilayer and protein-lipid contacts were studied by the fluorescence of 1,6-diphenylhexatriene and pyrene probes. Membrane hydrophobic properties according to intensity of 1,6-diphenylhexatriene fluorescent probe are found to depend both on the exposure time and the gas-discharge device used (Figure 3).

Membrane hydrophobicity grows with the increase of the time during which the lymphoid cell suspension is irradiated by DBK-9 mercury lamp and Brig device by 


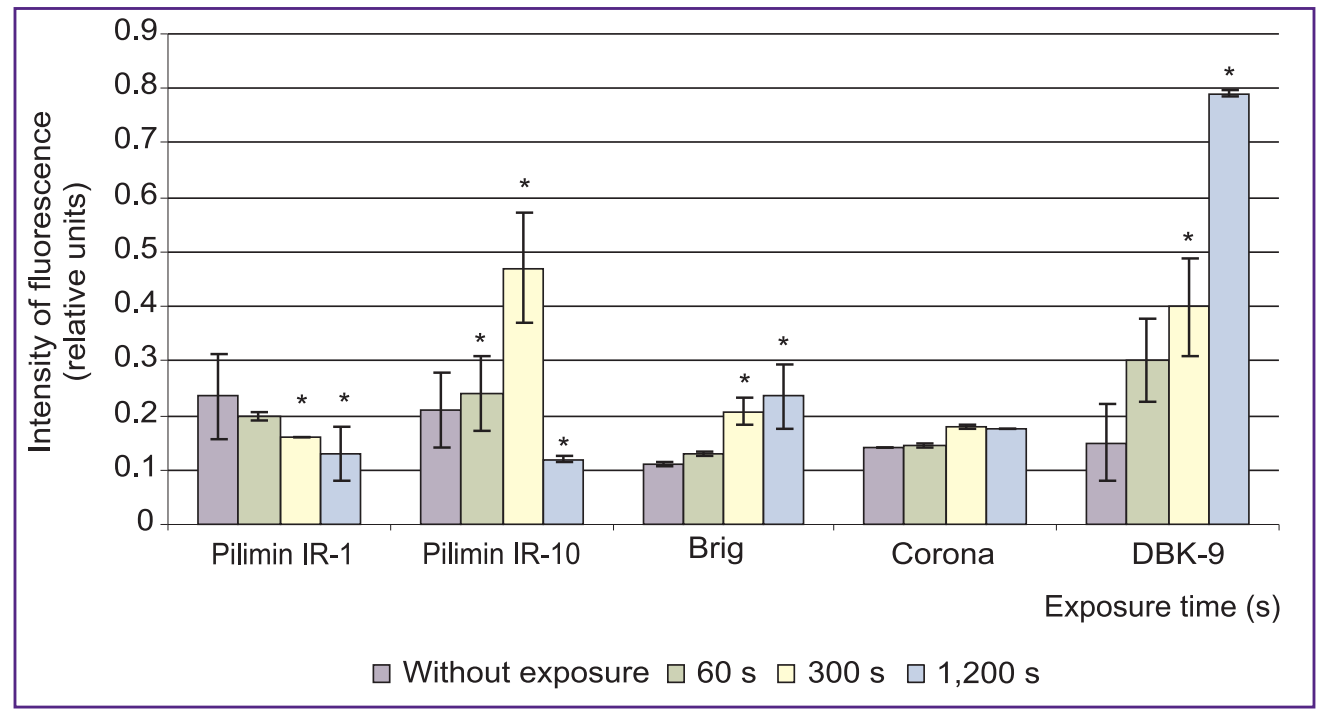

Figure 3. Intensity of 1,6-diphenylhexatriene fluorescence in the bilayer of lymphoid cells after irradiation by gas-discharge devices; * statistical significance of differences with the control group, $p<0.05$

5.3 and 2 times, respectively, which may speak of the consolidation of the phospholipid bilayer due to oxidation of the fatty acid double bonds, and, eventually, of the membrane permeability reduction [14]. When irradiated by spark discharge plasma of Pilimin IR-1 and IR-10 devices, hydrophobicity decreases 1.76 and 1.75 times, respectively, with the increase of exposure time. In this case hydrophobicity reduction is likely to be associated with loosening of the phospholipid bilayer and increase of the cell permeability [14]. Hydrophobicity of the membranes after irradiation by Corona does not change, consequently, the membrane permeability and the oxidation level of fatty acid phospholipids do not change either.

Microviscosity of the lipid bilayer and proteinlipid contacts was studied by means of eximerization of the pyrene probe. It was estimated that with the increase of time of irradiation by spark discharge plasma devices Pilimin series IR-1 and IR-10 and Brig, microviscosity of lymphoid cell bilayer diminishes 1.5 times (Figure 4 (a)), and, consequently, motility of fatty acid phospholipid chains grows. Exposure to ultraviolet radiation of DBK-9 mercury lamp for 1,200 s results in microviscosity increase by $32 \%$, speaking of the reduction of phospholipid motility and probable decrease of membrane permeability. No statistically significant differences of membrane hydrophobicity after exposure to Darsonval corona discharge were revealed.

Fluorescent pyrene probe is known to bind to fatty acid phospholipid and to incorporate into the hydrophobic areas. Pyrene fluorescence is sensitive to the changes in the micro-environment of proteins and lipids [10].

The microviscosity of the protein-lipid contacts (Figure 4 (b)) diminishes in the process of irradiation by Pilimin series IR-1 and IR-10 and DBK-9 mercury lamp by 1.9, 2.4 and 4.07 times, respectively. Two-fold increase of microviscosity is observed under the action of Brig plasma.

From the works by Loura et al. [15] it is known that pyrene binds covalently to the protein side chains in the phospholipid bilayer, therefore, increase as well as decrease of pyrene eximerization testifies to the destruction of covalent binds of proteins and lipids after irradiation. Alteration of such parameters as microviscosity and hydrophobicity will impair the work of the cell transport ATPases and receptor systems, change membrane permeability, and eventually lead to cell death [16].

Thus, all examined devices possess cytotoxic and membranotoxic effects. However, erythrocytes are more resistant to Darsonval corona discharges and spark discharge plasma with 1-10 $\mu$ s pulse duration, though they are less resistant to ultraviolet radiation of the mercury lamp and spark discharge plasma with a high pulse duration. Lymphoid cells of Pliss lymphosarcoma are more sensitive to the irradiation by spark discharge plasma and corona discharge with a short pulse duration, and are more resistant to ultraviolet radiation of the mercury lamp as well as spark discharge plasma with $1,500 \mu$ s pulse duration.

Radiation of spark discharge plasma and ultraviolet radiation of the mercury lamp induce damage to the cell membrane structures, i.e. possess more pronounced membranotoxic effect, whereas the cytotoxic effect of Darsonval corona discharge is likely to be more linked with metabolic changes in the cell than with disturbances in membrane phospholipids. Radiation of spark discharge plasma with $150 \mu$ s pulse duration exhibits equally membranotoxic and cytotoxic effects. 


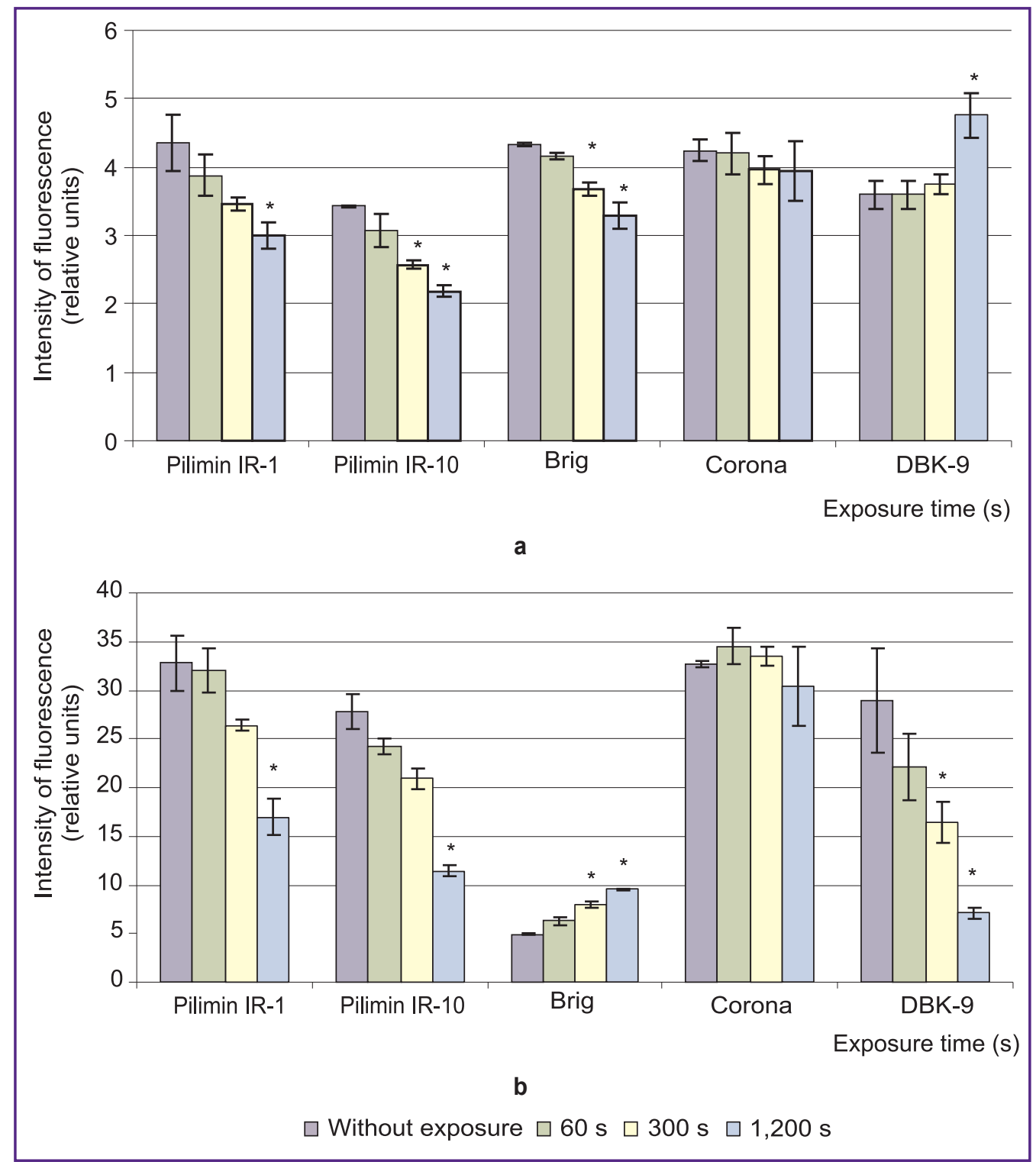

Figure 4. Change of microviscosity of phospholipid bilayer (a) and protein-lipid contacts of lymphoid cells (b) after irradiation by gas-discharge devices determined by the intensity of pyrene probe fluorescence; * statistical significance of differences with the control group, $p<0.05$

Conclusion. The results of assessing cytotoxic effect of various gas-discharge devices help to determine the direction of investigations when mechanisms of action of gas-discharge technologies are explored, and to recommend, in particular, a more profound study of such parameter as pulse discharge duration.

Study Funding and Conflicts of Interest. The work was not supported by any source, and there are no conflicts of interest related to this study.

\section{References}

1. Sasai Y., Kondo S., Yamauchi Y., Kuzuya M. Plasma surface modification of polymer substrate for cell adhesion control. J Photopolym Sci Technol 2010; 23(4): 595-598, https://doi.org/10.2494/photopolymer.23.595.

2. Steinbeck M.J., Chernets N., Zhang J., Kurpad D.S., Fridman G., Fridman A., Freeman T.A. Skeletal cell differentiation is enhanced by atmospheric dielectric barrier discharge plasma treatment. PLoS One 2013; 8(12): e82143, https://doi.org/10.1371/journal.pone.0082143.

3. Ivanova I.P., Zaslavskaya M.I. Biocydic effect of the spark discharge non-coherent impulse radiation in experiments in vitro and in vivo. Sovremennye tehnologii v medicine 2009; 1: 28-31.

4. Piskarev I.M., Ivanova I.P., Trofimova S.V. Comparison of chemical effects of UV radiation from spark discharge in air and a low-pressure mercury lamp. High Energy Chemistry 2013; 47(5): 247-250, https://doi.org/10.1134/ s0018143913050093. 
5. Ziskin M.C. Millimeter waves: acoustic and electromagnetic. Bioelectromagnetics 2012; 34(1): 3-14, https://doi.org/10.1002/bem.21750.

6. Ivanova I.P., Prodanets N.V., Spirov G.M. Morphological alterations of internal organs of the rats with transplantable Pliss' lymphasarcoma exposed to incoherent pulse radiation. Morfologiya; 2004; 4: 52.

7. Arkhipova E.V., Ivanova I.P. The effect of non-coherent impulse radiation on functional status of mononuclear cells in experiment. Sovremennye tehnologii $v$ medicine 2013; 5(1): 27-31.

8. Ivanova I.P., Trofimova S.V., Vedunova M.V., Zhabereva A.S., Bugrova M.L., Piskaryov I.M., Karpel Vel Leitner N. Assessment of cytotoxic effect mechanisms of gas-discharge plasma radiation. Sovremennye tehnologii $v$ medicine 2014; 6(1): 14-22.

9. Ivanova I.P., Trofimova S.V., Karpel Vel Leitner N., Aristova N.A., Arkhipova E.V., Burkhina O.E., Sysoeva V.A., Piskaryov I.M. The analysis of active products of spark discharge plasma radiation determining biological effects in tissues. Sovremennye tehnologii v medicine 2012; 2: 20-30.

10. Bains G., Patel A.B., Narayanaswami V. Pyrene: a probe to study protein conformation and conformational changes. Molecules 2011; 16(12): 7909-7935, https://doi. org $/ 10.3390 /$ molecules 16097909 .

11. Drahota Z., Palenickova E., Endlicher R., Milerova M.,
Brejchova J., Vosahlikova M., Svoboda P., Kazdova L., Kalous M., Cervinkova Z., Cahova M. Biguanides inhibit complex I, II and IV of rat liver mitochondria and modify their functional properties. Physiol Res 2014; 63(1): 1-11.

12. Salcedo-Sicilia L., Granell S., Jovic M., Sicart A., Mato E., Johannes L., Balla T., Egea G. BIII spectrin regulates the structural integrity and the secretory protein transport of the Golgi complex. J Biol Chem 2012; 288(4): 2157-2166, https:// doi.org/10.1074/jbc.m112.406462.

13. Dzhuzha D.A. Diagnostic efficacy of positron emission tomography with 18F-fluorodeoxyglucose in oncology. Onkologiya 2010; 12(3): 296-303.

14. Ibarguren M., López D.J., Escribá P.V. The effect of natural and synthetic fatty acids on membrane structure, microdomain organization, cellular functions and human health. Biochim Biophys Acta 2014; 1838(6): 1518-1528, https://doi.org/10.1016/j.bbamem.2013.12.021.

15. Loura L.M.S. Lateral distribution of NBD-PC fluorescent lipid analogs in membranes probed by molecular dynamics-assisted analysis of Förster resonance energy transfer (FRET) and fluorescence quenching. Int $\mathrm{J} \mathrm{Mol}$ Sci 2012; 13(12): 14545-14564, https://doi.org/10.3390/ ijms131114545.

16. Alakhova D.Y., Kabanov A.V. Pluronics and MDR reversal: an update. Mol Pharm 2014; 11(8): 2566-2578, https://doi.org/10.1021/mp500298q. 